\title{
The Evaluation of In Vitro Effects of Dipyridamole on Coronary Artery Bypass Grafts
}

\author{
Turan Ege', Okay Güven Karaca', Özcan Gür1', Hakan Karadağ², Selami Gürkan'1, Enver Duran¹ \\ ${ }^{1}$ Department of Cardiovascular Surgery, Faculty of Medicine, Trakya University, Edirne, Turkey \\ ${ }^{2}$ Department of Pharmacology, Faculty of Medicine, Trakya University, Edirne, Turkey
}

\begin{abstract}
Objective: The aim of this study is to evaluate the efficacy of dipyridamole in relieving the vasospasm of coronary artery bypass grafts.

Material and Methods: Twenty two patients who underwent elective coronary artery bypass grafting (CABG) were admitted to the study (Men/Women:14/8, mean age: $62.4 \pm 8.8$ years). Ten samples from left internal mammary(LIMA), radial arterial (RA) and saphenous vein (SV) grafts were collected for each. The samples were transported to the vascular laboratory in $4^{\circ} \mathrm{C}$ Krebs solution. Submaximal smooth muscle contraction was achieved first by 10-7M of phenylephrine solution. Dipyridamole was then added, starting from a concentration of 10-9M to a concentration of 10-3.5 M in two minutes intervals and half logarithmic dose increments. The concentration-response curves were obtained of the vasodilatation response relative to the begining.

Results: In the LIMA graft samples, the vasodilation response to dipyridamole was $43.2 \pm 1.6 \%$ and $97.6 \pm 4.1 \%$ at concentrations of $10-6 \mathrm{M}$ and $10-3.5 \mathrm{M}$ respectively. In RA graft samples, the vasodilation response to dipyridamole was $36.3 \pm 1.8 \%$ and $95.3 \pm 2.7 \%$ at concentrations of $10-6 \mathrm{M}$ and $10-3.5 \mathrm{M}$ respectively. In SV graft samples, however, the vasodilation response to dipyridamole was $43.2 \pm 1.4 \%$ and $96.6 \pm 2.2 \%$ at concentrations of $10-6 \mathrm{M}$ and 10-3.5M respectively.
\end{abstract}

Conclusions: The amplitude of relaxation response to dipyridamole of all grafts samples were similar, without statistically significant difference among the IMA, RA and SV grafts in the in vitro tissue bath system. These results prove that dipyridamole has a potential use as a vasodilatatory drug in all graft types.

Key Words: Dipyridamole, coronary artery bypass graft, left internal mammarian artery, radial artery, saphenous vein.

Received: 19.04.2010 Accepted: 12.05 .2010

\section{Introduction}

The importance of coronary artery bypass grafting (CABG) and the different types of grafts consequently has increased due to a rising incidence of cardiovascular diseases. In CABG, myocardial ischemia is relieved by the use of grafts resulting in a higher quality of life in patients. The internal mammary artery (IMA), radial artery (RA) and saphenous vein (SV) grafts are the most frequently used grafts for this purpose (1-3). The choice and preparation of the optimum graft is critical in the long term graft patency. Mechanical trauma or the pharmacological agents used during the preparation of the graft are known to have a negative impact on long term graft patency (1-3). Several studies have addressed the ways to prevent spasm of arterial or venous grafts. Vasodilators like papaverin, diltiazem and nitroglycerine are widely used for this purpose but the data on the efficacy of dipyridamole is very limited.

Dipyridamole, which was first introduced 50 years ago as a coronary vasodilator, increases interstitial adenosine concentration by blocking adenosine uptake and relieves ischemia. It is widely used in coronary and peripheral arterial disease, restenosis and stroke (4).
The aim of this study is to evaluate the efficacy of dipyridamole in relieving vasospasm of coronary artery bypass grafts under in vitro conditions.

\section{Material and Methods}

\section{Graft Sampling}

Twenty two patients ( 14 men and 8 women) were included in the study after the approval of the local ethics committee. The mean age was $62.4 \pm 8.8$ (42-77) years. Ten samples were studied for LIMA, RA and SV grafts each. In total, 30 vessel samples were studied in an organ bath setting.

\section{Organ Bath}

The LIMA and RA grafts were collected together with the adjacent vein, fascia and adipose tissue with the aid of dissection scissors. The graft tissues were not exposed to any vasodilator drug. The SV samples were collected without being inflated to prevent barotrauma. The samples were transported to the vascular laboratory in $4^{\circ} \mathrm{C}$ Krebs solution, which contained $(\mathrm{mM}) \mathrm{NaCl} 122, \mathrm{KCl} 5, \mathrm{CaCl}_{2} 1.25, \mathrm{NaHCO}_{3} 25, \mathrm{MgSO}_{4}$ 1.2, $\mathrm{KH}_{2} \mathrm{PO}_{4} 1.0$, glucose 11.5. Ten mililiters of solution found 
in the tissue bath was continously oxygenated by $95 \% \mathrm{O}_{2}$ and $5 \% \mathrm{CO}_{2}$. The grafts were dissected from the adjacent tissues and was sliced into $3 \mathrm{~mm}$ width vascular rings under the microscope. The vascular rings were suspended into the classical tissue bath system via steel hooks. The upper end of the hook was attached to a tension transducer and the lower end was kept stable. Active tension of 1 to $4 \mathrm{gr}$, was applied to all of the samples. The vascular rings were suspended under this tension for a minimum of 60 minutes. The samples were kept alive by $37^{\circ} \mathrm{C}$ oxygenated Krebs solution baths every $20 \mathrm{~min}$ utes. In order to measure the relaxation response, the samples were exposed to phenylephrine (Merck, Turkey) $\left(10^{-7} \mathrm{M}\right)$ first for submaximal constriction. Dipyridamole (Persantin Ampule, Boehringer Ingelheim, Spain) was then added starting from a concentration of $10^{-9} \mathrm{M}$ in two minutes intervals and the dose incremented half logarithmically until a concenration of $10^{-3.5} \mathrm{M}$ was reached. The concentration-reponse curves were obtained. The data were transferred to the computer with the help of the Transducer Acquisition System (COMMAT TDA10-A, COMMAT, Turkey) and was stored as POLWIN97.

\section{Statistical analysis}

The statistical analysis of the data was performed by Graphpad Prism 4 Version Demo. The concentration-response curves were also constructed by this program. Nonlinear regression analysis (variable slope) and one way ANOVA were applied to the graphics. A value of $p<0.05$ represented the statistically significance cut-off value.

\section{Results}

The vasodilatation response to dipyridamole was studied in phenyephrine pre-treated graft samples. In the LIMA graft samples, the vasodilatation response to dipyridamole was $43.2 \% \pm 1.6 \%$ at a concentration of $10^{-6} \mathrm{M}$ and reached its maximal response (97.6 4.1 ) at a concentration of $10^{-3.5} \mathrm{M}$ (Figure 1).

In RA graft samples, the vasodilatation response to dipyridamole was $36.3 \% \pm 1.8 \%$ at a concentration of $10^{-6} \mathrm{M}$ and was $95.3 \% \pm 2.7 \%$ at a concentration of $10^{-3.5} \mathrm{M}$ (Figure 2).

In SV graft samples, however, the vasodilatation response to dipyridamole was $43.2 \pm 1.4 \%$ at a concentration of $10^{-6} \mathrm{M}$ and was $96.6 \% \pm 2.2 \%$ at a concentration of $10^{-3.5} \mathrm{M}$ (Figure 3 ).

Figure 4 demonstrates the vasodilatation response curves of all three tissue samples reveal the fact that no statistically significant difference exists among the samples, all of which respond with the same amount of vasodilatation.

\section{Discussion}

Dipyiridamole, which is a well-known antiplatelet drug, has also been demonstrated to inhibit human and rabbit vascular smooth muscle cell proliferation in vitro. Dipyridamole acts through the metabolism and transport of adenosine by preventing the reuptake of adenosine by erythrocytes and other cells, increasing intravascular adenosine levels and thereby reducing the cyclic adenosine monophosphate (cAMP) intracellularly, causing vasodilatation (5-10). Due to its vasodilatatory feature, it is a widely used drug in coronary and peripheral vascular diseases (11-13).

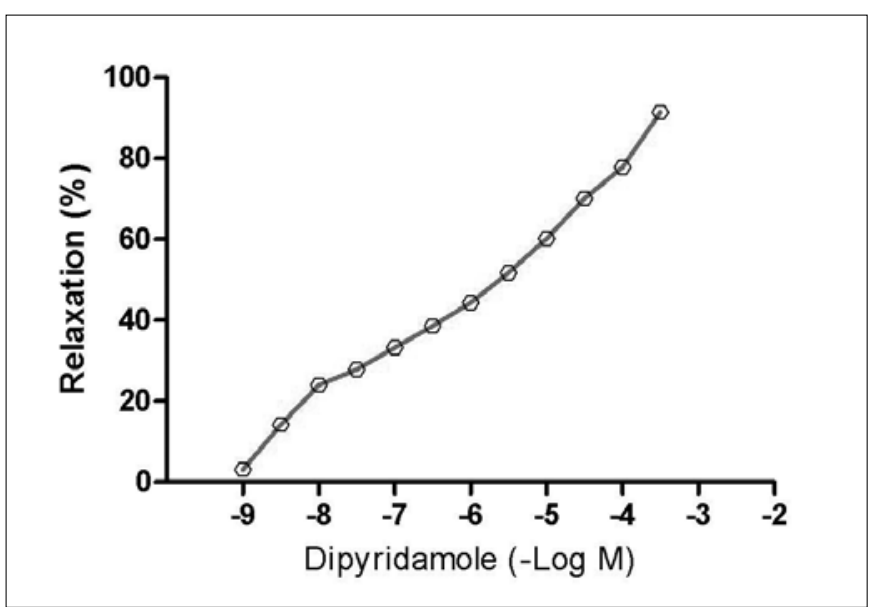

Figure 1. Dipyridamole induced relaxation response in left internal mammary artery graft samples

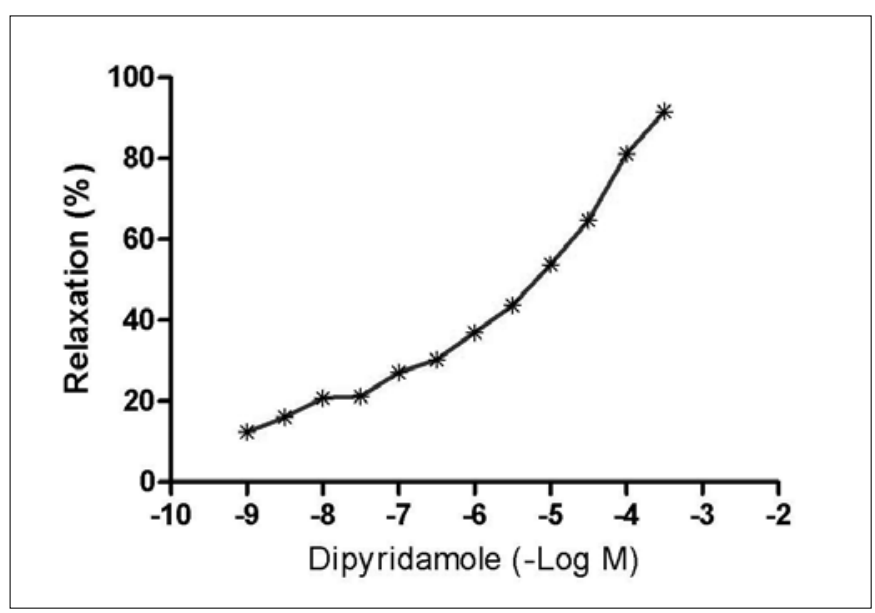

Figure 2. Dipyridamole induced relaxation response in radial artery graft samples

In patients with $C A B G$, anginal symptoms may recur because of progressive aterosclerosis in the native coronary arteries or occlusion of grafts for various reasons. Dipyridamole stress testing is frequently used in this setting for the evaluation of angina and graft flow (14-17). This test studies the grafts in vivo. However, there are no studies conducted to show the effect of dipyridamole on grafts in vitro. We studied the effect of dipyridamole on IMA, RA and SV grafts in a tissue bath system. The pre- constricted samples of IMA, RA and $\mathrm{SV}$ grafts dilated by the same amount with dipyridamole. The relaxation response increased directly proportional to increasing concentrations of dipyridamole.

It is well known that trauma or vasospasm of the graft during its collection or preparation unfavourably affects the long term graft patency. Since the use of electrocautery during the collection can disrupt the constriction-relaxation response, we used dissection scissors insead of electrocautery.

Papaverin, diltiazem and nitrogylcerin are widely used to prevent the induction of vasospam during the preparation of the graft $(1,2)$. Therefore, we did not use any vasodilatory agent either, in order not to disrupt the constriction-relaxation response of the grafts. 


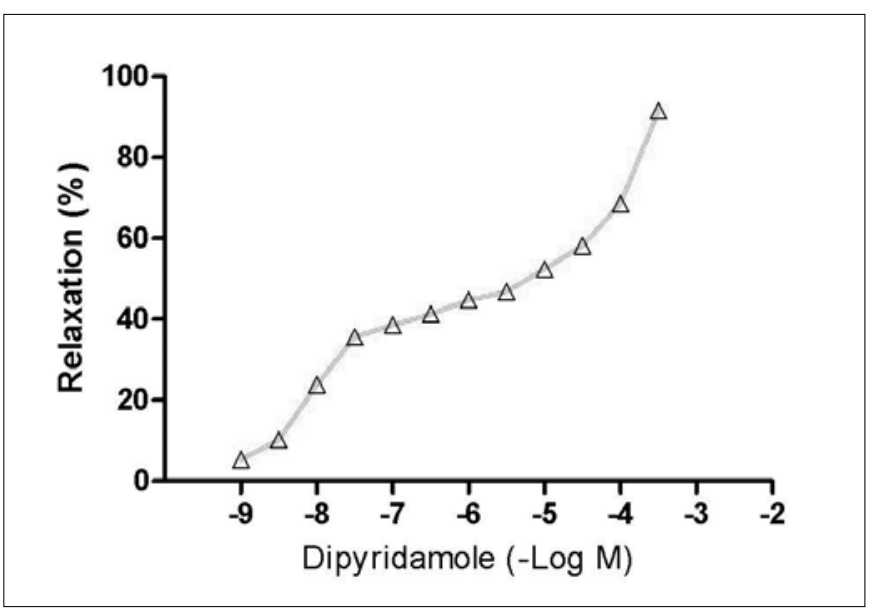

Figure 3. Dipyridamole induced relaxation response in saphenous vein graft samples

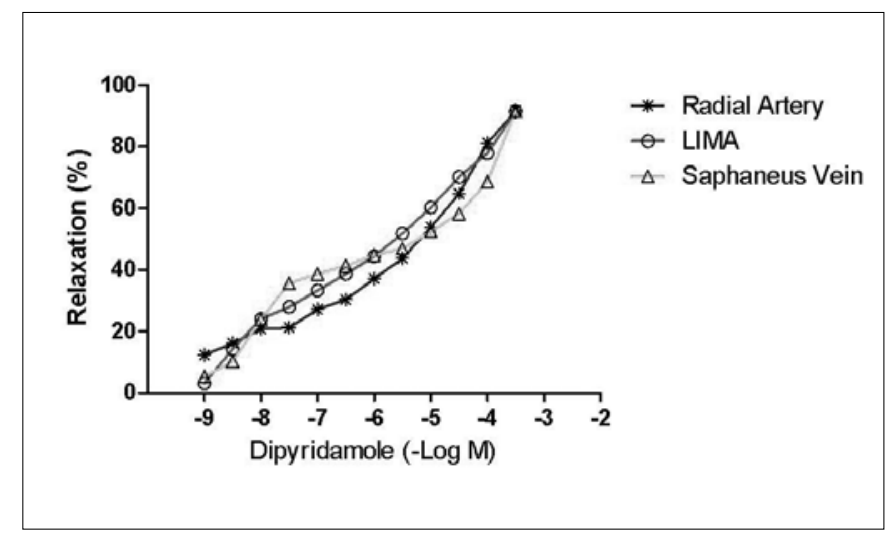

Figure 4. Dipyridamole induced relaxation response in left internal mammary artery, radial artery and saphenous vein graft samples

Chrillo et al. (14), investigated the augmentation of flow rates in IMA and SV grafts by dipyridamole induced stress echocardiography in patients with CABG. They found the same amount of increase with dipyridamole both in SV and IMA grafts. This in vivo experiment is in concordance with our in vitro findings.

Vroom et al. (9), used phosphodiesterase III enzyme inhibitors and demonstrated vasodilatation in small arteries independent of potassium channels or nitric oxide release. However, we studied both larger sized arteries and veins, where we showed that dipyridamole has the same vasodilatory effects on both.

In conclusion, dipyridamole induced vasodilatation response studied in an in vitro tissue bath system has produced the same amount of vasodilatation in all IMA, RA and SV grafts.

\section{Conflict of Interest}

No conflict of interest was declared by the authors.

\section{References}

1. He GW. Arterial grafts for coronary artery bypass grafting: Biological characteristics, functional classification, and clinical choice. Ann Thorac Surg 1999;67:277-84. [CrossRef]

2. Nisanoglu V, Battaloglu B, Ozgur B, Eroglu T, Erdil N. Topical vasodilators for preventing radial artery spasm during harvesting for coronary revascularization: comparison of 4 agents. Heart Surg Forum 2006;9:807-12. [CrossRef]

3. Santos JMG, Rodriguez JL, Sorli MJD. Arterial grafts in coronary surgery, treatment for everyone? Rev Esp Cardiol 2005;58:1207-23.

4. Eisert WG. Dipyridamole. In: Michelson AD. editor. Platelets, 2nd ed. Academic Pres: 2007. p.1165-79 [CrossRef]

5. Laurence B, John L, Keith P, editors. Goodman and Gilman's the pharmacological basis of therapeutis. 11th ed. New York (NY): McGraw- Hill; 2006.

6. Hegedüs K, Keresztes T, Fekete I, Molnar L. Effect of i.v. dipyridamole on cerebral blood flow, blood pressure, plasma adenosine and cAMP levels in rabbits. J Neurol Sci 1997;148:153-61. [CrossRef]

7. Veeranna V, Potluri K, Mahmood S, MacDonalt L. Asystole during dipyridamole administration. Indian J Med Sci 2009;63:363-4. [CrossRef]

8. Zhu W, Masaki T, Cheung AK, Kern SE. Cellular pharmacokinetics and pharmacodynamics of dipyridamole in vascular smooth muscle cells. Biochem Pharmacol 2006;72:956-64. [CrossRef]

9. Vroom MB, Pfaffendore M, van Wezel HB, van Zwieten PA. Effect of phosphodiesterase inhibitors on human arteries in vitro. $\mathrm{Br} \mathrm{J}$ Anaesth 1996;76:122-9.

10. Barba G, Mullen MJ, Donald A, Macallister RJ. Determinants of the response of human blood vessels to nitric oxide donors in vivo. J Pharmacol Exp Ther 1999;289:1662-8.

11. Cassar K, Bachoo P, Brittenden J. The role of platelets in peripheral vascular disease. Eur J Vasc Endovasc Surg 2003;25:6-15. [CrossRef]

12. Stein PD, Schünemann HJ, Dalen JE, Gutterman D. Antithrombotic therapy in patients with saphenous vein and internal mammary artery bypass grafts: the seventh ACCP conference on antithrombotic and thrombolytic therapy. Chest 2004;126;600-8. [CrossRef]

13. Stein PD, Dalen JE, Goldman S, Schwartz L, Theroux P, Turpie AG. Antithrombotic therapy in patients with saphenous vein and internal mammary artery bypass grafts. Chest 1995;108:424-30. [CrossRef]

14. Chirillo F, Bruni A, Balestra G, Cavallini C, Olivari Z, Thomas JD, et al. Assessment of internal mammary artery and saphenous vein graft patency and flow reserve using transthoracic Doppler echocardiography. Heart 2001;86:424-31. [CrossRef]

15. Gibbons RJ, Araoz PA, Williamson EE. The year in cardiac imaging. J Am Coll Cardiol 2009;53:54-70. [CrossRef]

16. De Luca AJ, Cusack E, Aronow WS, Monsen CE. Sensitivity, specifity, positive predictive value, and negative predictive value of the dipyridamole sestamibi stres test comparing arterial to vein conduits. Chest 2004;126:1040-1.

17. Pezzano A, Fusco R, Child M, Riccobono S, Milazzo A, Recalcati $F$, et al. Assessment of left internal mammary artery grafts using dipyridamole doppler echocardiography. Am J Cardiol 1997;80:1603-6. [CrossRef] 